\title{
Diskoid menisküs
}

\author{
Discoid meniscus
}

\author{
Gökhan Ayık¹, Çağlar Yılgör², Gazi Huri ${ }^{1}$, Egemen Turhan¹, Özgür Ahmet Atay ${ }^{1}$
}

\author{
${ }^{1}$ Hacettepe Üniversitesi Tıp Fakültesi Ortopedi ve Travmatoloji Anabilim Dalı, Ankara
}

${ }^{2}$ Acıbadem Üniversitesi Tıp Fakültesi, Ortopedi ve Travmatoloji Anabilim Dalı, İstanbul

Lateral menisküs; boyut, kalınlık, şekil ve mobilite açısından mediyal menisküse göre daha fazla çeşitlilik gösterir. En sık görülen lateral menisküs varyantı ise diskoid menisküstür. Diskoid menisküs, diz ekleminin tipik olarak anormal morfolojisi ve lateral menisküsün potansiyel instabilitesini içeren konjenital bir varyanttır. Bu durumda menisküs normal olması gerekenden daha kalındır ve tibiayı örtme oranı artmıştır. Diskoid menisküs; artmış kalınlığa, zayıf doku kalitesine, instabiliteye ve sekonder yırtılmaya eğilimlidir. Birçok stabil lateral menisküs varyantı asemptomatik olarak seyreder ve insidental olarak saptanır. Semptomatik hastalarda ise sıklıkla daha çok çocukluk çağı ve adolesan yaşta görülen diz fleksiyonu ile oluşan klik sesi, ağrı, azalmış eklem hareket açıklığı, eklem çizgisi üzerinde hassasiyet, diz ekleminde yabancı cisim hissi, kuadriseps kas atrofisi ve eklem effüzyonu görülmektedir. Fizik muayene özellikle intrartiküler patoloji ile uyumlu ise oldukça sensitiftir. Manyetik rezonans görüntüleme ise tanıyı konfirme etme ve tedaviye yön verecek bilgiler verme açısından değer taşımaktadır. Diskoid menisküs ilk tanımlandığından bugüne kadar klinik, radyolojik ve artroskopik bulgulara göre birçok sınıflama sistemi ortaya atılmıştır. Bu sınıflamaların birçoğu tanımlayıcıdır ve tedaviye yön verme konusunda fazla bilgi vermemektedir. İdeal bir tedavisi henüz bilinmemektedir. Genel olarak tedavi; gözlem, yeniden şekillendirme, parsiyel menisektomi, total menisektomi ve instabil lezyonlar için periferik tamir gibi seçeneklerden oluşmaktadır. Cerrahi dışı tedavinin başarısız olduğu durumlarda artroskopik tedavi endikedir. Tarihsel olarak, total menisektomi semptomları başarılı bir şekilde hafifletmiş, ancak diz ekleminde dejeneratif değişikliklerle birlikte kötü sonuçlara neden olmuştur. Bu nedenle, menisküsün olabildiğince korunması, yeniden şekillendirme ve ihtiyaç halinde onarım tercih edilen tedavi seçeneğidir. Tedavi sonuçları için uzun takip sürelerine sahip çalışmalara ihtiyaç vardır.

Anahtar sözcükler: diskoid menisküs; lateral menisküs; menisküs yırtığı; diz
Lateral meniscus has more varieties regarding to size, thickness, shape and mobility, compared to the medial meniscus. The most common variation of the lateral meniscus is discoid meniscus. Discoid meniscus is a congenital variant that typically involves abnormal morphology of the knee joint and potential instability of the lateral meniscus. Discoid meniscus is thicker than usual, and the coverage rate on the tibia is increased. Discoid menisci are prone to tears secondary to increased thickness, poor tissue quality, and instability. Many stable lateral meniscus variants are asymptomatic and are found incidentally. Symptomatic patients often have 'clunk' sound with knee flexion especially during childhood and adolescence; pain, decreased range of motion, tenderness on the joint line, foreign body sensation in the knee joint, quadriceps muscle atrophy and joint effusion. Physical examination is particularly sensitive if it is consistent with intraarticular pathology. MRI is used for confirming the diagnosis and planning treatment. Since the discoid meniscus was first described, many classification systems have been proposed, according to clinical, radiological and arthroscopic findings. Many of these classifications are descriptive, and do not give much information about treatment. An ideal treatment is not yet known. Treatment options consist of observation, saucerization of the meniscus, partial meniscectomy, total meniscectomy, and peripheral repair for unstable lesions. Arthroscopic treatment is indicated when non-surgical treatment is unsuccessful. Historically, total meniscectomy has relieved symptoms suc-cessfully, but has poor results with degenerative changes in the knee joint. For this reason, meniscus should be protected as much as possible, saucerization and if necessary repair is the preferred treatment option. Long-term follow-up studies are needed to determine outcomes.

Key words: discoid meniscus; lateral meniscus; meniscus tear; knee

- Illetişim adresi: Dr. Ahmet Özgür Atay, Hacettepe Üniversitesi Tıp Fakültesi Ortopedi ve Travmatoloji Anabilim Dalı, Ankara Tel: 0533 - 2058585 e-posta: oaatay@hacettepe.edu.tr

- Geliș tarihi: 1 Mart $2018 \quad$ Kabul tarihi: 1 Mart 2018 


\section{TARIHÇE}

Diskoid menisküs; farklı menisküs şekil ve stabilitelerini içeren bir spektruma sahip konjenital bir varyanttır. Genellikle lateral menisküste görülmektedir. Illk olarak Young tarafindan 1889 yllında kadavra spesimenlerinden tarif edilmiştir. Kroiss, 'snapping knee' sendromunu diskoid menisküse bağlamıştı. ${ }^{[1]}$ Daha kesin tanı ve sınıflama ile ilgili bilgiler ise geç dönemde ortaya çıkmıştır.

\section{EMBRIYOLOJi}

Normal menisküsler, erken fetal gelişim evresinde, ekstremite tomurcuğu çevresinde mezenkimal dokudan farklılaşmaktadır. Bunlar, ilk olarak gestasyonun 8. haftasında net olarak belirmekte ve olgun anatomik şekillerine 14. haftada ulaşmaktadır. ${ }^{[2]}$ Önceleri erişkin hilal şeklindeki menisküsün, embriyolojik dairesel bir diskten zamanla merkezde apoptozis görülmesi sonrası oluştuğu, bu apoptozisin görülmemesi durumunda ise diskoid olarak kaldığı düşünülmekteydi. Fakat sonraki araştırmalarda, normal gelişim basamaklarının hiçbir döneminde menisküsün diskoid bir şekle sahip olmadığı görülmüştür. ${ }^{[3]}$ Bu bilginin saptanması, problemin nedeninin belirlenmesi konusunda oldukça önemlidir.

Menisküs vaskülaritesi, yaşamın ilk 10 yılında yavaş yavaş azalmaktadır. Doğumda tüm menisküs vaskülerdir. Doğum sonrası 9. aya gelindiğinde ise sadece dış $2 / 3$ 'ü vasküler olmaktadır. On yaşına gelindiğinde ise vaskülarite tipik bir erişkin menisküsü ile uyumlu olmaktadır. ${ }^{[4]}$

\section{ANATOMI}

Lateral menisküs, $C$ şeklindeki mediyal menisküse göre daha sirküler bir görünüme sahiptir. Normal lateral menisküs, bir çemberin $5 / 6$ 'sıdır ve ortalama $12 \mathrm{~mm}$ bir genişliğe, 4-5 mm bir yüksekliğe sahiptir. Menisküslerin periferik üçte birlik kısmı vaskülerdir ve 'red zone' olarak bilinir; tersine santral üçte birlik kısım ise avaskülerdir, 'white zone' olarak bilinir ve sinovyadan diffüzyon yoluyla beslenmektedir. ${ }^{[4]}$

Erişkinlerde $C$ şeklinde mediyal menisküs, tibia platosunun \%50'sini örtmekte ve koroner, meniskotibial ve derin mediyal kollateral bağlar ile kapsüle sıkıca bağlanmaktadır. Lateral menisküs ise tibia platosunun \%70'sini örtmekte ve sıkı anterior-posterior bağlantılara sahiptir. Popliteal hiatus ve fibular kollateral bağ ile bir bağlantısı olmadığından, lateral eklem kapsülü ile olan bağlantısı oldukça zayıftır. Bu nedenle, mediyal menisküse göre daha fazla bir mobilitesi vardır. Lateral tibial plato üzerinde daha fazla yer değiştirme olanağına sahiptir. Lateral menisküsün posterior boynuzu, anterior ve posterior meniskofemoral bağlar (Wrisberg ve Humphrey) ile mediyal femoral kondilin lateral yüzeyine bağlanmaktadır. Bu bağlar, arka çarpraz bağın önünde ve arkasında olmalarına göre isimlendirilir. Wrisberg arka çarpraz bağın arkasından, Humphrey ise önünden geçmektedir. Bu yapılar oldukça farklılık gösterebilmektedir. ${ }^{[5]}$ Lateral menisküsün posterior üçte birlik kısmı, popliteus kasından güçlü bağlantılar almaktadır. Bu sayede diz fleksiyonu sırasında menisküsün posteriora doğru çekilmesi sağlanır. Popliteus tendonu ile beraber lateral menisküs diz eklemini, aşırı posterolateral rotasyonel kuwvetlere karşı stabilize eder.

Diskoid lateral menisküsler ise daha kalındır ve normal menisküsten daha az vaskülarite gösterir. ${ }^{[6]}$ Diskoid menisküs, tibial platonun normal yüzeylerine göre daha geniş bir yüzeyi kaplar ve hatta tüm lateral platoyu (gerçek disk) kapsayabilir. Ultrastrüktürel olarak, diskoid menisküs, normal menisküslere göre daha dağınık bir şekilde seyreden, daha az sayıda kollajen lifine sahiptir. ${ }^{[7]}$ Intrameniskeal mukoid dejenerasyon da yaygın olarak görülebilmektedir. Papadopoulos ve ark., diskoid menisküslerdeki dezorganize sirkumferensial kollajen ağının, menisküs yapısında zayıflığa neden olduğunu ve dolayısıyla yırtığa eğilimi arttırdığını göstermiştir. ${ }^{[8]}$

Varyasyonlar, şekil olarak normal fakat hipermobil olabilmektedir. Çeşitli anormal insersiyonlar ya da anormal görünümler (sirküler-yüzük şeklinde menisküs) bu duruma neden olabilmektedir.[5,9-11]

\section{EPIDEMIYOLOJi}

Diskoid lateral menisküsün gerçek insidansını saptamak çok sayıda asemptomatik olgudan dolayı güç olmaktadır. Prevalans; inceleme metodu, seçilen kriterler ve hasta popülasyonuna göre değişmektedir. ABD'de popülasyonun $\% 3$ ile $\% 5$ 'inde görüldügü tahmin edilmektedir. ${ }^{[12]}$ Japon popülasyonunda ise prevalansın \%15'lere kadar yüksek oranda olduğunu gösteren çaIışmalar bulunmaktadır. ${ }^{[12,13]}$ Wrisberg tipinin en az görüldüğü tahmin edilmektedir. ${ }^{[14]}$

Komplet diskoid menisküslü çocukların, unilateral ya da bilateral, inkomplet diskoid menisküslülere göre cerrahi müdahale gerektirme oranı yaklaşık 4,5 kat daha fazla saptanmıştır. ${ }^{15]}$ Bilateral görülme prevalansı ise dünya çapında yaklaşık olarak \%15-25 arasında değişebilmektedir. ${ }^{[16-18]}$ Fakat bilateral diskoid menisküsün gerçek insidansı yine asemptomatik olgulardan dolayı net olarak bilinmemektedir. Ahn ve ark., unilateral semptomatik diskoid menisküs nedeni ile artroskopik cerrahiye gidecek 33 hastanın kontralateral diz manyetik rezonans (MR) görüntülerini değerlendirmiş ve hastaların \%97'sinde karşı dizde komplet veya inkomplet diskoid menisküs bulduklarını belirtmişlerdir. ${ }^{[19]}$ 
Yine erken dönemde, açık menisektomi yapılan semptomatik hastalardaki çalışmalarda, diskoid lateral menisküs prevalansının \%2-5 arasında olduğu söylenmiştir. ${ }^{[20,21]}$ Sonraki dönem artroskopik çalışmalarda ise prevalansın \%0,4 ve \%16,6 arasında değiştiği gösterilmiştir. ${ }^{[22-26]}$ Kadavra çalışmalarında ise $\% 0$ ve $\% 7$ arasında değişen prevalans oranları saptanmıştır. ${ }^{[27,28]}$ Diskoid menisküs, Asya ülkelerinde diğer bölgelere göre daha sık görülmektedir. ${ }^{[14,23]}$

\section{ETIYOLOJi}

Lateral menisküs anomalilerin altında yatan nedenler multifaktöriyeldir. Bu nedenleri açıklamak için geçmişten günümüze birçok teori ortaya atılmıştır.

Smillie ${ }^{[21]}$, normal gelişim sırasında menisküsün santral kartilajinöz disk bölümünün rezorpsiyonunun az olması nedeniyle diskoid görünümde olduğu hipotezini ortaya atmıştır. Fakat daha sonra yapılan çalışmalarda, embriyolojik gelişimin hiçbir basamağında menisküslerin diskoid şeklinde olmadığı gösterilmiştir. ${ }^{[2,3]}$

Kaplan ${ }^{[3]}$, normal şekildeki bir menisküsün, çevresel anormal bağlantıları nedeni ile mediyal-lateral bir hareketi olabileceğini ve bu durumun tekrarlayan travmalar nedeniyle menisküs şeklinde değişiklik yapabileceğini ortaya atmıştır. Ekstansiyon sırasında, meniskofemoral bağlardaki tansiyon nedeni ile menisküs posteromediyal doğrultuda çentiğe doğru sublukse olmakta; fleksiyonda ise kapsül ve popliteusun çekmesi nedeni ile tekrar ekleme doğru redükte olmaktadır. Posterior tibial yapışma bölgesinin anormal olarak yetersizliği bir formasyon bozukluğuna ve filogenetik bir tamamlanmamaya neden olabilmektedir. ${ }^{[29]}$ Sirküler menisküs ${ }^{[5]}$ bu duruma kanıt olarak gösterilmektedir. $\mathrm{Bu}$ teorinin eksik yönü ise normal bağlantılara sahip stabil diskoid menisküsleri açıklayamamasıdır.
Bazı yazarlar konjenital bir kökeni desteklemektedir. Woods ve Whelan ${ }^{[28]}$, instabil diskoid menisküsün önce konjenital stabil bir diskoid menisküs şeklinde başladığını, zamanla artmış makaslama kuvvetleri nedeni ile posterior kapsüler seperasyon sonucu instabil olduğunu ortaya atmışlardır. Diğer instabil tiplerin nedenleri ise daha az nettir. Watanabe ve ark. (1979) Wrisberg tipini, normal şekilde fakat anormal bağlantıları olan menisküs şeklinde tanımlamışlardır. Bundan sonra, diğer instabil varyantlar bu kategoriye dahil edilmiştir.

$\operatorname{Kaplan}^{[3]}$, tekrarlanan travma nedeniyle anormal yapışmaları olan normal şekilli bir menisküs tanımlamıştır. Sonrasında, stabil olan diskoid menisküsün, makaslama kuvvetleri nedeni ile instabil olması tanımlanmıştır. $^{[28,30]}$ Üçüncü bir olasılık ise posterior tibial yapışmaları olmayan diskoid menisküstür. Dördüncü tip olarak da normal şekilli fakat posterior tibial yapışmalarında yetersizlik olan menisküs de tanımlanmıştır. ${ }^{[22]}$ Bunların hepsi; instabil menisküs nedeniyle benzer semptomlara neden olabilen geniş yelpazedeki anomali spektrumunun birer parçasıdır. Tüm instabil tiplerde subluksasyona ve redüksiyona izin veren meniskofemoral bağ olup olmadığı net bilinmemektedir. ${ }^{[12]}$ Meniskofemoral bağlantı varlığında primer patolojinin posterior tibial bağlantıdaki yetersizlikten kaynaklandığı düşünülmektedir. Meniskofemoral bağ adeta bir dizgin gibi davranmakta, dislokasyondan ziyade subluksasyon ve redüksiyona izin vermektedir.

\section{SINIFLAMA}

En yaygın kullanılan sınıflama sistemi 1969 yılında Watanabe ve ark. tarafından önerilmiştir (Şekil 1). ${ }^{[20]}$ Bu sistemde diskoid menisküsler artoskopik görünüm ve stabiliteye göre sınıflandırılmıştır. Üç tip diskoid menisküs tanımlanmıştır;

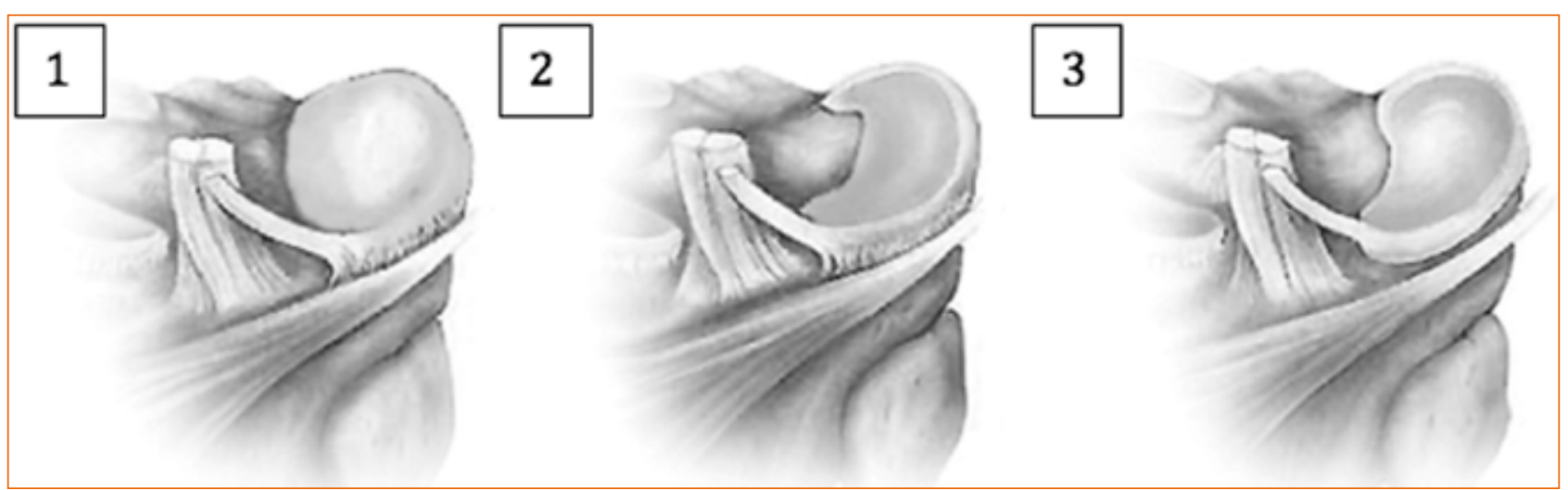

Şekil 1. Watanabe sınıflaması. 
- Tip I-Stabil, komplet diskoid menisküs; prob ile muayenede stabildir, blok şeklindedir ve tüm platoyu kapsar.

- Tip II-Stabil, inkomplet diskoid menisküs; prob ile muayenede stabildir ve tibial platonun \%80'ine kadar uzanabilmektedir.

- Tip III-Stabil olmayan, Wrisberg varyantı; prob ile muayenede posterior meniskotibial bağlantıların olmaması nedeniyle instabilite saptanır. Tip III'teki tek posterior bağlantı, Wrisberg'in meniskofemoral bağıdır.

Wrisberg tipi, posterior tibial bağlantılardaki yetmezlik nedeniyle hipermobil fakat neredeyse normal şekilli bir menisküs olarak tanımlanmış ve bundan sonra diskoid olsun olmasın tüm instabil menisküsler Wrisberg tipine dahil edilmiştir. ${ }^{[3,26,28]}$

Bu klasik sınıflama 1998 yılında genişletilmiştir. ${ }^{[9]}$ Normal posterior yapışması olan yüzük şeklinde (ringshaped) menisküs, dördüncü bir tip olarak sınıflamaya dahil edilmiştir.

Diskoid lateral menisküslerin periferik rim instabilite prevalansı için yapılan bir çalışmada 128 diskoid lateral menisküs incelenmiş. İntraoperatif olarak sınıflandırılan menisküslerin \%62'sinde tam morfoloji olduğu gösterilmiştir. Çalışılan tüm dizlerin \%70'inde menisküs yırtığı olduğu ve \%28'inde periferik rim instabilitesi olduğu görülmüştür. Tarihsel olarak, posterior menisküs kapsüler instabilitesi, diskoid menisküs ile ilişkiliydi. Sonrasında ise buna ek olarak anterior ve orta instabilite tanımlandı. Diskoid menisküste periferik rim instabilite paternleri en sık anterior boynuz $(\% 47,2)$, ardından posterior boynuz $(\% 38,9)$ ve son olarak orta üçte birlik $(\% 11,1)$ bölümde görülmektedir. Periferik rim instabilitesinin genç hastalarda daha yaygın olduğu, stabil diskoid menisküsler ile karşılaştırıldığında ise stabil olmayanların daha genç yaşta semptomatik hale gelebileceği gösterilmiştir. ${ }^{[17]}$

Jordan (1996), artroskopik ve klinik bulgulara dayaII, tedaviyi yönlendiren ve çeşitli lateral menisküs tiplerini tanımlayan yeni bir sınıflama sistemi önermiştir (Tablo 1). ${ }^{[12]}$
Son zamanlarda ${ }^{[31]}$ MR bulgularına göre bir sınıflama sistemi önerilmiştir. Seksen iki diz üzerinde yapılan çalışmada, bulgular dört kategoriye ayrılmıştır;

1) Kayma yok: diskoid menisküsün periferik kısmı kapsülden ayrılmamıştır ve menisküs deplase değildir.

2) Anterosantral kayma: posterior boynuzun periferi kapsülden ayrışmıştır, menisküs anterior ve anterosantrale deplase olmuştur, anterior boynuz sagittal kesitlerde kalınlaşmış görülmektedir.

3) Posterosantral kayma: anterior boynuzun periferi kapsülden ayrışmıştır, menisküs posterior ve posterosantrale deplase olmuştur, posterior boynuz sagittal kesitlerde kalınlaşmış görülmektedir.

4) Santral kayma: posterolateral bölümün periferi kopmuş ve gevşemiştir, tüm menisküs çentiğe doğru santrale deplase olmuştur.

Sonuç olarak da kayma olanların, olmayanlara göre tamir ve subtotal menisektomiye daha fazla oranda gittiği gösterilmiştir.

\section{YIRTIKLAR (Şekil 2-4)}

Diskoid menisküslerde yırtık görülme sıklığı özellikle 15 yaşından sonra artmaktadır. ${ }^{[32,33]}$ Diskoid menisküs $\% 38$ ve \%88 arasında değişen oranlarda artmış yırtık insidansı ile ilişkilendirilmiştir. ${ }^{[11,34]}$ En sık görülen patern ise, tüm semptomatik diskoid lateral menisküs yırtıklarının \%58-98'ini oluşturan dejeneratif horizontal klivaj yırtıklarıdır. ${ }^{[16,35,36]}$

O'Connors sınıflamasının modifikasyonu ile lateral menisküs varyant yırtıkları altı sınıfa ayrılmaktadır ${ }^{[7]}$;

1) Basit horizontal yırtıklar,

2) Kombine horizontal yırtıklar (majör komponenti horizontaldir ${ }^{[34]}$ ),

3) Periferal yırtığı içeren longitudinal yırtıklar,

4) Oblik ya da flap yırtığını içeren radiyal yırtıklar,

5) Dejeneratif yırtığı içeren kompleks yırtıklar (horizontal yırtık dışında iki majör komponenti içeren veya horizontal yırtığı içeren üç ya da daha fazla majör komponenti içeren kombinasyonlar) ve

Tablo 1. Jordan'ın yeni sınıflama sistemi

\begin{tabular}{llll}
\hline Sınıflama & Korelasyon & Yırtık & Semptomlar \\
\hline Stabil & Komplet/Inkomplet & Yes/No & Yes/No \\
Diskoid şekilli instabil & Wrisberg tip & Yes/No & Yes/No \\
Normal şekilli instabil & Wrisberg varyantı & Yes/No & Yes/No
\end{tabular}




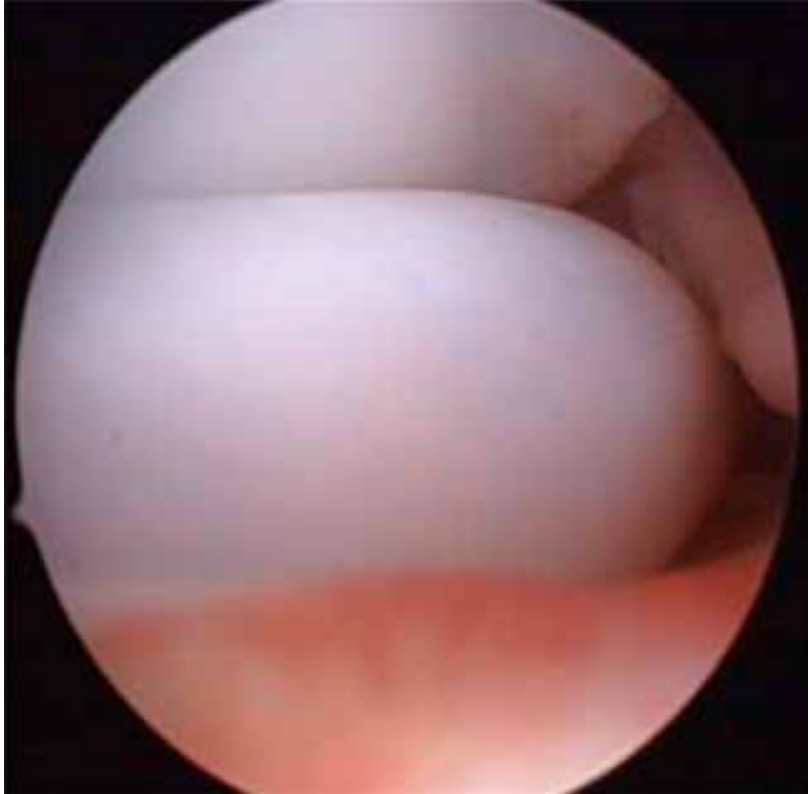

Şekil 2. Komplet diskoid menisküs artroskopik görüntüsü.

6) Santral yırtıklar (tekrarlayan maserasyonlar sonucunda diskoid menisküs santral kısmının geniş bir spektrumda aşınmasına bağlı olarak oluşan yırtıklar). ${ }^{[37]}$

\section{KLINIK}

Diskoid menisküs değişken bir sunuma sahiptir, semptomatik olabilir veya olmayabilir. Birçoğu insidental olarak saptanabilir. Bilateral olarak bulunup unilateral şeklinde de semptom verebilir. Hastanın karşı taraf alt ekstremite muayenesi de önem taşımaktadır.

Yırtık ya da instabil diskoid menisküsün klasik semptomları ise diz ağrısı, daha çok çocukluk ve adolesan çağda görülen diz fleksiyonunda oluşan klik sesi, terminal ekstansiyonda azalmadır. ${ }^{[38]}$ Bunun yanı sıra, eklem çizgisinde hassasiyet, diz ekleminde yabancı cisim hissi, kuadriseps kas atrofisi ve effüzyon da saptanabilmektedir. ${ }^{[13,16,22,26,30,32,38]}$

Semptomlar, hastanın yaşından, diskoid menisküs instabilitesinden ve yırtığın olup olmamasından etkilenir. On yaş altı çocuklar, aralıklı ve spontan olarak, dizden ses gelmesi ve tam ekstansiyona getirememe semptomları gösterebilirler. ${ }^{[2]}$ Lateral eklem çizgisinde bir şişkinlik ve McMurray testinde bir 'clunk' saptanabilir. Daha ileri yaş çocuklarda ise yırtılma semptomları olan ağrı, şişlik ve mekanik semptomlar görülebilmektedir. ${ }^{[3,39]}$

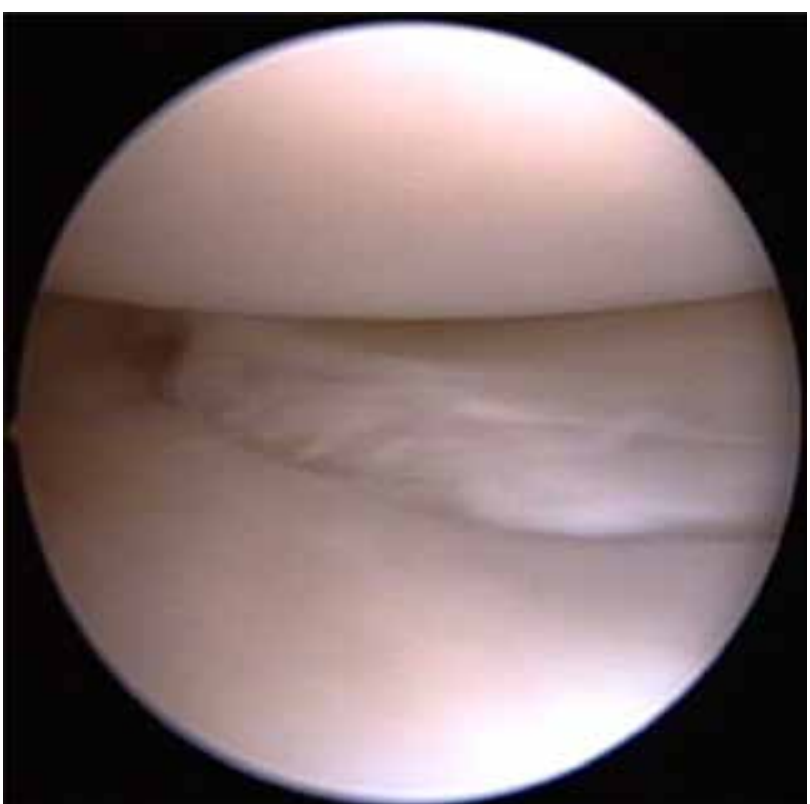

Şekil 3. Radyal yırtık artroskopik görüntüsü.

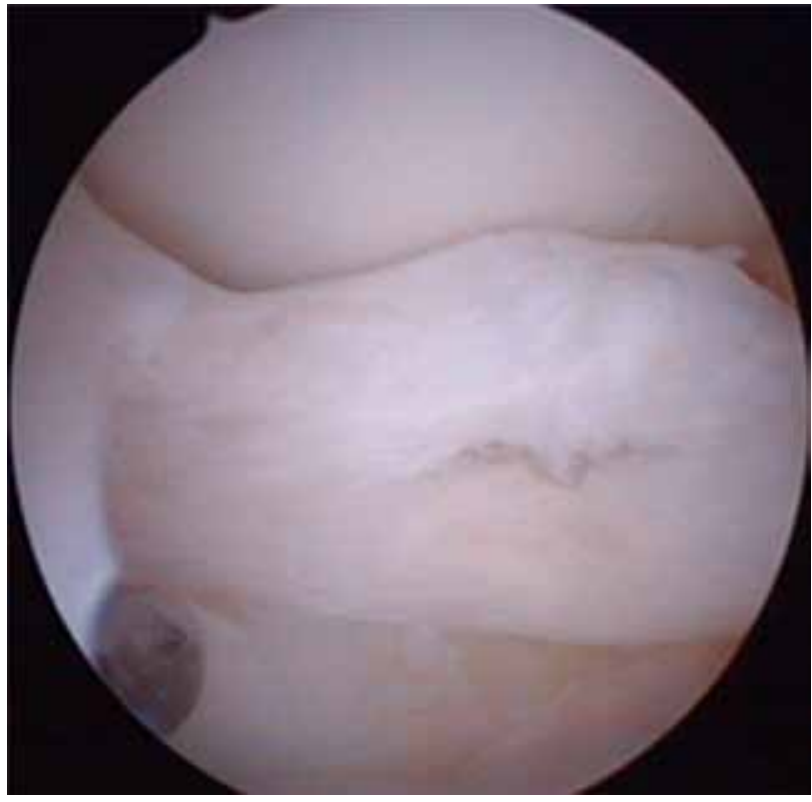

Şekil 4. Komplet diskoid menisküs-horizontal yırtık.

Ahn ve arkadaşlarına göre diskoid menisküs tipi, semptomlar ile bağlantılıdır. Yaptıkları çalışmada, menisküs anterior boynuz kalınlığının 7,7 mm'den fazla olduğu durumlarda ekstansiyon kısıtlılığının sık görüldüğünü, 4 mm'den az olduğu durumlarda ise ekstansiyon kısıtlılığının görülmediğini göstermişlerdir. ${ }^{[40]}$ 


\section{EŞLIK EDEN DURUMLAR}

Diskoid lateral menisküs, diğer musküloskeletal anomaliler ile birlikte görülebilmektedir. Bunlar arasında yüksek fibula başı, fibular musküler defektler, lateral eklem mesafesinin açılması ile giden lateral femoral kondil hipoplazisi, lateral tibial eminens hipoplazisi, anormal şekilli lateral malleol ve genişlemiş inferior genikulat arter sayılabilir. ${ }^{[14]}$

Osteokondritis dissekans, genellikle genç hastalarda görülen ve subkondral kemik ve kartilajın parsiyel ya da komplet olarak seperasyonu ile giden bir hastalıktır. Insidansı görece azdır, fakat diskoid lateral menisküs ile birlikteliği oldukça zorlu bir klinik durum ortaya çıkarır. ${ }^{[16,41,42]}$ Genellikle kötü prognozlu olmaktadır. Yırtık oluşmasa bile, diskoid menisküsün kendisi lateral femoral kondilde anormal bir kontakt güç oluşturur. $\mathrm{Bu}$ anormal güç, lateral femoral kondilde osteokondritis disekansa neden olur. ${ }^{[33]}$ Yine yapılan çalışmalarda lateral femoral kondil osteokondritis dissekanslarının çoğunda lateral diskoid menisküs varlığı rapor edilmiştir. $^{[41]}$ Lateral femoral kondil osteokondritis dissekansı için predispozan faktörler arasında; lateral diskoid menisküs yırtığı, genç yaş, yüksek aktivite ve valgus dizilimi bulunur. Yapılan parsiyel menisektominin ise osteokondritis dissekans iyileşmesine yardımcı olduğu gösterilmiştir. ${ }^{[41]}$

\section{RADYOLOJI: X-RAY}

Direkt radyografiler özellikle akut bir yaralanma sonrası tüm çocuklarda görülmelidir. Bunlar arasında; anteroposterior, lateral, tünel ve 'sunrise' ya da 'Merchant' grafileri vardır.

Radyoloji normal olabilir, fakat saptanan bazı bulgular ile hastalığın şiddeti görülebilir. Bunlar arasında; lateral femoral kondil kareleşmesi, tibial platonun çukurlaşması, lateral eklem mesafesinde genişleme, hipoplastik lateral tibial spine sayılabilir. ${ }^{[44]} \mathrm{Bu}$ bulgular, karşı taraf diz ile karşılaştırılarak daha net ayırt edilebilmektedir. ${ }^{[45]}$ Osteokondritis dissekans ve lateral malleol anomalileri gibi durumlar da yine eşlik eden patoloji olarak saptanabilir.

\section{RADYOLOJi: ULTRASONOGRAFI (US)}

Menisküs, ultrasonografide geniş, irregüler ve diskoid şekilli görülmektedir. US, kolay uygulanabilirliği, multi-planar değerlendirme sağlaması ve ekonomik olması nedeniyle menisküs yırtıklarını değerlendirmek için kullanılabilmektedir. Yüksek rezolüsyonlu mikrokonveks problar ile popliteal fossaya daha iyi girilebilmekte ve menisküs yırtıklarını saptamada daha duyarlı ve özgül olunabilmektedir. Dezavantajı ise kişiye bağımlı olmasıdır. Diskoid menisküsün US kriterleri arasında; normal triangüler şeklin görülmemesi, anormal şekilde elonge olmuş ve kalın meniskal dokunun görülmesi, heterojen santral paternin saptanması sayllabilir. ${ }^{[14]}$

\section{RADYOLOJi: MR GÖRÜNTÜLEME (Şekil 5 ve 6)}

MR görüntüleme, diskoid menisküs tanısında ve morfolojisini belirlemede oldukça önemli bir araçtır. ${ }^{[19,46]}$ Tanı kriterleri arasında; koronal görüntüde serbest kenar ile menisküsün periferi arasındaki mesafenin $15 \mathrm{~mm}$ üstünde olması, $5 \mathrm{~mm}$ kalınlıktaki sagittal kesitlerde menisküsün anterior ve posterior boynuzları arasında üç veya daha fazla kesitte devamlılık görülmesi (papyon bulgusu) sayılabilir.

Menisküsün anterior boynuzu, posterior boynuzu dahil tüm dokuları ölçülmelidir. Koronal görüntüde $>2$ mm yükseklik farkı veya transvers çapta $>15 \mathrm{~mm}$ olması diskoid menisküs lehinedir. ${ }^{[14]}$

MR ayrıca, lateral diskoid menisküsün doku içi yırtıklarını ve dejenerasyonlarını da gösterebilmektedir. ${ }^{[47]}$ Fakat yırtık tipini belirlemede yetersiz kalabilir. ${ }^{[48]}$

Genel olarak MR, lateral diskoid menisküs tanısı için fizik muayeneden daha düşük bir duyarlılığa sahiptir. Kocher yaptığı çalışmada, 16 yaş altı çocuk ve adolesanların eklem içi diz bozukluklarının değerlendirilmesinde klinik muayene ve MR tanısal performanslarını karşılaştırmıştır. Genel olarak, artroskopik bulgularla uyum açısından fizik muayene ile MR arasında istatistiksel olarak anlamlı bir fark saptanmamıştır. Ancak, tanısal olarak yapılan analizde lateral diskoid menisküs duyarlıı̆̆ı açısından anlamlı bir fark saptanmıştır (\%88,9 klinik muayene; \%38,9 MR p=0,002). Bu bulgular ile, pediatrik popülasyonda diskoid menisküs tanısında selektif MR'nin fizik muayeneden daha iyi olmadığı çıkarılabilmektedir. ${ }^{[46]}$

Bazı yazarlar, MR'nin rutin kullanımının zor olduğunu, artroskopinin hem tanı hem de tedavi amaçlı kullanılabileceğini söylemektedir. ${ }^{[32]}$ Son yıllarda çıkan bir yazıda, MR'nin diskoid menisküste yırtık olup olmadığını gösterme konusunda başarılı, fakat yırtık tipini saptama konusunda tartışmalı olduğu belirtilmektedir. ${ }^{[47]}$

\section{TEDAVi}

Uygun tedavi için hastanın yaşı, aktivite seviyesi, lezyonun anatomisi, semptomların süresi ve uzanı$\mathrm{mı}$, eklem harabiyeti göz önünde bulundurulmalıdır. Aslında, diskoid menisküs bulunan bir diz en baştan beri anormaldir ve dolayısıyla ideal bir tedaviden bahsedilememektedir. ${ }^{[14]}$ Diskoid menisküsün doğal seyri, 


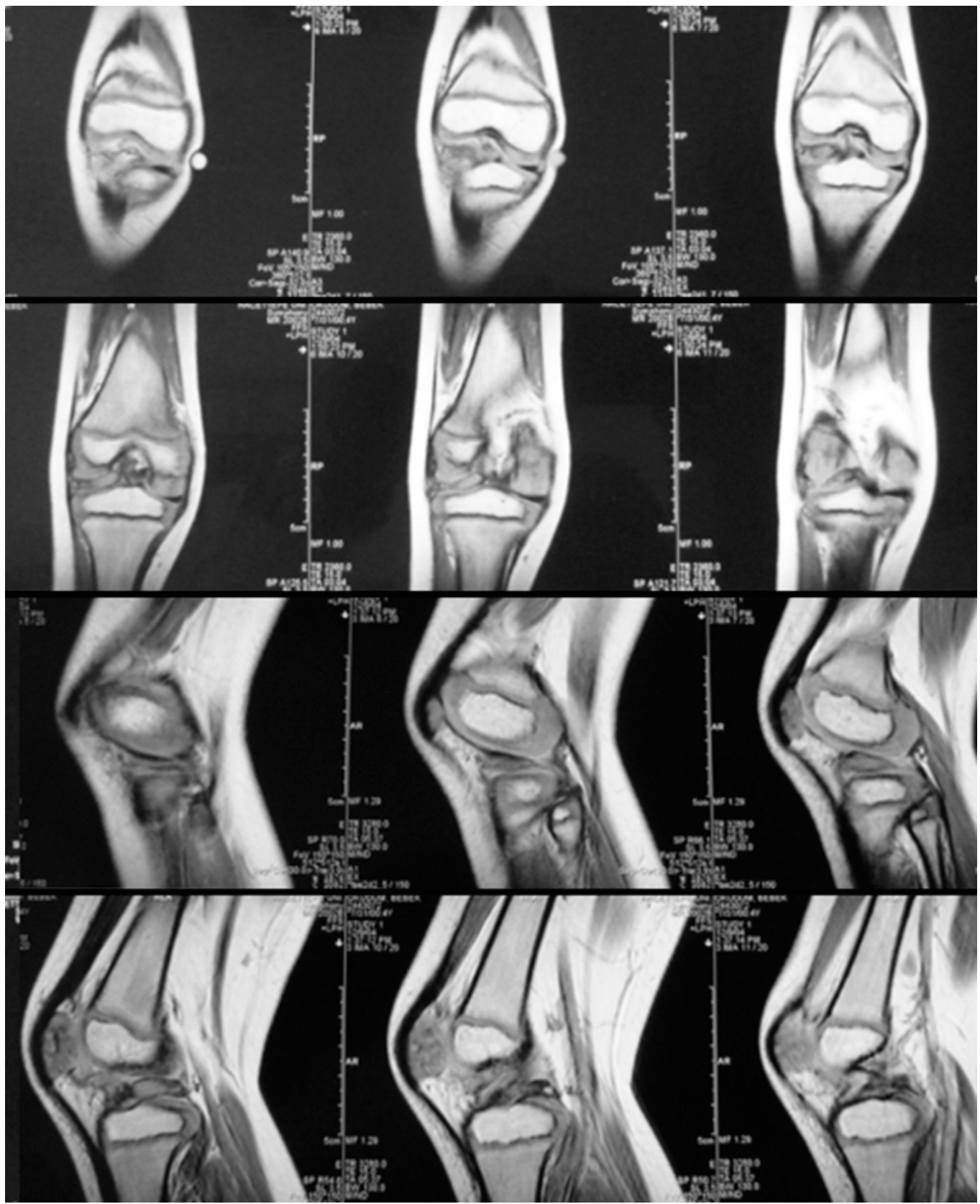

Şekil 5. Komplet diskoid menisküs ve horizontal yırtık ardışık görüntüleri.

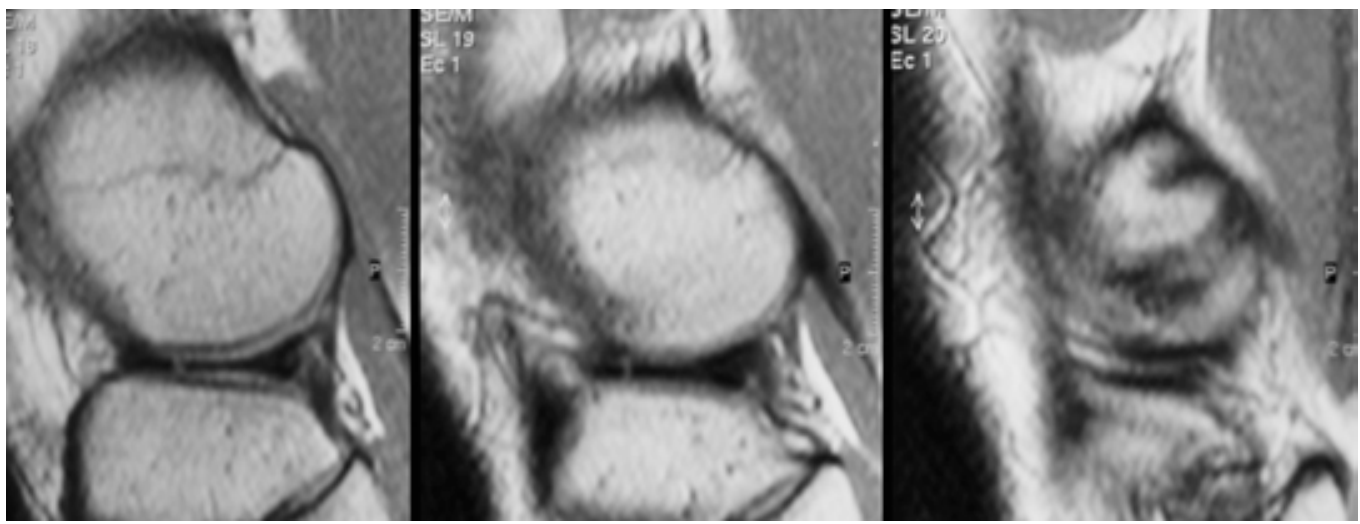

Şekil 6. İnkomplet diskoid menisküs ve radyal yırtık ardışık görüntüleri. 
semptomatik ya da asemptomatik diskoid menisküsün cerrahi yapılmayanlarının uzun süreli takibi hakkında yeterli bilgi bulunmamaktadır. ${ }^{[49]}$

Gözlem, asemptomatik veya palpabl bir klik mevcudiyeti, fakat ağrısız tam eklem hareket açıklığı olan minimal semptomatik çocuklarda uygundur. Yine aynı şekilde, asemptomatik olan, ameliyat öncesi MR ile saptanamayan ve ek bir patoloji için yapılan artroskopide insidental olarak saptanan diskoid menisküslerin, yırtık olmadıkça veya instabilite yaratmadıkça tedavi edilmesine gerek duyulmamaktadır. ${ }^{[9]}$ Zamanla, diz eklemi diskoid morfolojiye adapte olup iyi bir gözlem ile yeterli fonksiyon sağlayabilir. ${ }^{[26]}$

Cerrahi müdahale, semptomatik diskoid menisküslerde endikedir. Tarihsel olarak bakıldığında, stabil semptomatik lezyonda tercih edilen tedavi total menisektomiydi. ${ }^{[6,21]}$ Fakat, lateral non-diskoid menisküslerin total olarak çıkarılmasının, sıklıkla osteoartrite neden olduğu bilinmektedir. ${ }^{[50,51]}$ Bu durum, erişkin diskoid menisküslerde de geçerlidir. Çocukluk çağında ise, menisektomi sonrası lateral dejeneratif artrit riski erişkinlere göre daha fazladır. Bu nedenle eğer mümkünse, çocuklarda diskoid menisküs tedavisinde total menisektomiden olabildiğince kaçınmak gerekir. ${ }^{[14]}$ Menisektomi yapılan, izole menisküs yırtığı bulunan 20 adolesan ve çocuk hastada yapılan bir çalışmada, 12 hastada tatmin edici olmayan sonuç elde edilmiş. 15 hasta semptomatik ve 16 hastada ise ortalama 5,5 yılda radyolojide osteoartrit bulguları saptanmıştır. ${ }^{[1]}$ Total menisektomi sonrasında ortalama 19,8 yıllık takipte, 17 dizin 10'unda osteoartrit semptomları ve osteoartrit ile uyumlu radyolojik değişiklikler, iki dizde ise lateral femoral kondilde osteokondral lezyon saptanmıştır. ${ }^{[52]}$

Menisküsler; yük dağılımında, şok absorpsiyonunda, sinoviyal sıvı dağılımında ve kartilaj beslenmesinde rol alan yapılardır. Normal yapıdaki menisküsler üzerinde yapılan parsiyel menisektomi sonrasında, çıkarılan miktara göre kontakt stres artar. ${ }^{[33]}$ Total menisektomi sonrasında kontakt alan \%75 oranında azalmakta, kontakt stres ise \%235 oranında artmaktadır. ${ }^{[53]}$ Menisküslerin normal eklem fonksiyonundaki öneminin gün geçtikçe anlaşılması, tedavi planında stabil menisküslerin olabildiğince korunmasına neden olmuştur. ${ }^{[14]}$

Semptomatik stabil, komplet veya inomplet diskoid lateral menisküs için günümüzdeki güncel tedavi artroskopik parsiyel menisektomidir. ${ }^{[23,30,35,54]}$ Geçmişte bazı yazarlar, yüksek reoperasyon oranları nedeniyle parsiyel menisektomi yerine total veya subtotal menisektomiyi önermişlerdir. ${ }^{[55]}$ Bunun arkasında ise, menisküs kenarındaki artmış kalınlığın, menisküs ile artiküler yüzey arasındaki uyumsuzluğa bağlı olarak yüksek makaslama kuvvetlerine maruz kalacağı ve anormal menisküs kenarının tekrar yırtığa predispoze olacağı düşüncesi yatmaktadır. Günümüzde ise önerilen, stabil bir kenarın, anormal dokudan oluştuğu düşünülse bile korunmasıdır. ${ }^{[25,26,28,36]}$ Parsiyel menisektomide en sık kullanılan yöntem tek-parça eksizyonudur. ${ }^{[4]}$ Birçok yazar, sıkışmayı önlemek, kalan parçanın instabil olarak ileride başka bir yırtığa neden olmasını önlemek ve rehabilitasyon süresini azaltmak için kalan periferal kenar kalınlığının 5-8 mm arasında olması gerektiğini savunmaktadır. ${ }^{[5,13,30]}$ Parsiyel menisektomi ve şekillendirme sonrasında stabilite mutlaka değerlendirilmelidir, çünkü instabil varyant içeren hastalarda stabilizasyon gerekliliği olabilir. Stabilizasyon all-inside, inside-out veya outside-in sütürler ile sağlanabilmektedir. Eşlik eden santral yırtıklar, boyutlarına, lokalizasyonlarına, yırtık paternlerine ve stabilite durumlarına göre, yeniden şekillendirme sırasında tamir edilebilir ya da parsiyel olarak çıkarılabilir. ${ }^{[49]}$

Artroskopi esnasında, bazı diskoid menisküsü olan semptomatik hastalarda yırtık görülemeyebilir. Bu nedenle, ameliyat öncesi MR tüm diskoid menisküs düşünülen hastalarda gereklidir. Kaymanın olup olmadığı, varsa yönü cerrahi öncesi mutlaka değerlendirilmelidir. Tedavi yaklaşımı, bu duruma göre farklılık gösterecektir. Kayma varsa, eksizyon öncesi menisküs mutlaka redükte edilmelidir. ${ }^{[56]}$ Rezeksiyon sonrası karşı boynuzdaki yırtık sütürlerle tamir edilebilir. ${ }^{[14]}$

\section{POSTOPERATIF REHABILITASYON}

Menisküs tamiri yapılmayan, sadece parsiyel menisektomi ve şekillendirme yapılan hastalar, cerrahi sonrası tam yük vererek mobilize olabilirler. Fizik tedaviye, ameliyat sonrası 2. haftada başlanabilir. Spora ya da rekreasyon aktivitelerine dönüşe ise, tam bir eklem hareket açıklığ ve kuvveti sağlandıktan sonra progresif olarak başlanır. Bu da, yaklaşık ameliyat sonrası 8 . hafta civarında mümkün olur. Menisküs onarımı da tedaviye dahil ise, hastaya diz hareketlerini kısıtlayıcı bir ortez verilir ve hasta kısmi yük vererek mobilize olur. Eklem hareket açıklığı kademeli olarak kazanılır ve tam yük vermeye ameliyat sonrası ortalama 6 . haftada başlanır. Spora dönüş ise, hastanın tam eklem hareket açıklı̆̆ ve kuvvetini kazanmasına göre değişir. Bu da, ameliyat sonrası yaklaşık 12-16 hafta sonra mümkün olur. ${ }^{[50]}$

\section{TEDAVI SONUÇLARI}

Tedavi sonuçlarını değerlendirmede Ikeuchi[ ${ }^{23]}$ sistemi ve Lysholm diz skalası ${ }^{[57]}$ kullanılabilir. Ikeuchi'nin sistemi, mekanik semptomlara, ağrı ve hareket açıklıklarına dayanmaktadır. Lysholm skalası ise numerik bir 
skaladır ve hasta, aksama, destek kullanımı, merdiven çıkma, squat, instabilite, şişlik, dizde ağrı ve uyluk atrofisine göre puan alır. ${ }^{[14]}$

Semptomatik diskoid menisküslerde yeniden şekillendirmenin kısa dönem sonuçları tatminkardır. Good ve ark. ${ }^{[58]}, 30$ semptomatik diskoid menisküslü dizi değerlendirmişlerdir. Bunların 28'inde artroskopik şekillendirme mümkün olmuştur. Ortalama hasta yaşı 10,1'dir. íki olguda, geniş kompleks yırtıkların bulunmasından dolayı komplet artroskopik menisektomi yapılmıştır. Olguların \%77'sinde (23/30) meniskeal instabilite saptanmıştır. Anterior boynuz instabilitesi saptanan tüm olgularda artroskopik outside-in teknikle, posterior boynuz instabilitesi saptanan tüm olgular$\mathrm{da}$ ise artroskopik inside-out teknikle tamir yapılmıştır. Yirmi bir hasta takip kriterlerini karşılamış ve hepsinde diz eklem hareket açıklığı $135^{\circ}$ 'nin ötesine geçmiştir. Ortalama takip süresi 37,4 aydır. Üç hastada rezidüel diz ağrısı, dört hastada aralıklı mekanik semptomlar saptanmıştır.

Öğüt ve ark. ${ }^{[59]}$, artroskopik şekillendirme yapılan 11 semptomatik diskoid lateral menisküslü dizi değerlendirmişlerdir. Ortalama yaş 11,5 ve ortalama takip süresi 4,5 yıldır. En son takipte, hastalar Ikeuchi sistemine göre sınıflandırılmıştır. Dokuz mükemmel sonuç (semptomsuz, tam eklem hareket açıklığı), iki iyi sonuç (ara sıra olan ağrı) saptanmıştır. Hiçbir hastada radyolojik olarak dejeneratif değişiklik görülmemiştir.

2003 yılında yapılan bir çalışmada Watanabe, komplet ve inkomplet tiplerde parsiyel menisektominin \%85 oranında mükemmel ve iyi sonuç verdiğini göstermiştir (Atay ve ark. 2003). Aynı yıl, çocuklarda menisküsün parsiyel rezeksiyonunun tercih edildiği, fakat komplet dislokasyonlarda total eksizyonun gerekli olabileceği söylenmiştir. ${ }^{[60]}$

Kırk sekiz semptomatik diskoid lateral menisküsün değerlendirildiği bir çalışmada, ortalama 10,1 yıllık takipte, sadece şekillendirme yapılan olgularda \%23 oranında, tamirle birlikte parsiyel menisektomi yapılan olgularda \%39 oranında, subtotal menisektomi yapılan olgularda ise \%88 oranında dejeneratif değişiklikler saptanmıştır. Ortalama hasta yaşı 9,9'dur. ${ }^{[61]}$

Hastanın yaşı, son klinik sonuçta önemli bir prognostik faktördür. ${ }^{[62]}$ Farklı yaş gruplarının karşılaştırmasında, yaşla beraber sonuçların kötüleştiği saptanmıştır. Cinsiyetin, diskoid lateral menisküs tipinin, menisküs yırtığı varlığının, semptomların süresinin klinik sonuçlar açısından prediktif olmadığı belirlenmiştir.

Carter ve ark. (2012), sadece şekillendirme yapılan ve ek olarak menisküs stabilizasyonu yapılan hastalar üzerindeki yaptıkları çalışmada, kısa takip süresinde (ortalama 15 ay) klinik sonuçlar açısından (ameliyat sonrası eklem hareket açıklığı, komplikasyon oranları) anlamlı fark saptamamışlardır. ${ }^{[39]}$ Yeniden şekillendirmenin kısa vadede sonuçları iyi gözükse de, özellikle lateral kompartman osteoartrit sürecini değerlendirebilmek için uzun takip sürelerine ihtiyaç vardır. ${ }^{[49]}$

Kısa dönem takibe sahip olan çalışmalarda, total menisektomi sonrasında semptomatik hastalarda meniskeal allogreftlerin kullanılabileceği gösterilmiştir. ${ }^{[63]}$ Yoon ve ark. ${ }^{[64]}$, total menisektomi sonrasında menisküs allogreft transplantasyonu yapılan 36 hastayı değerlendirmişlerdir. Bunların 16'sı yırtık diskoid menisküse sahipti. Ortalama takip süresi 32 aydı (diskoid grup için 38 ay, non-diskoid grup için 41 ay). Total menisektomiden transplantasyona kadar geçen süre, diskoid grupta ortalama 63,4 ay, non-diskoid grupta ise 34,7 aydı. Son takipte, eklem hareket açıklığı dışında, gruplar arasında ameliyat öncesi ve sonrası ağrı, aktivite skorları, 'International Knee Documentation Committee' skorları, Lysholm skorları, Tegner aktivite skalası açısından anlamlı fark saptanamamıştır. Eklem hareket açıklığı ise, diskoid grupta anlamlı olarak düşük saptanmıştır. Fakat, bu konuda uzun dönem çalışmalara ihtiyaç vardır.

\section{KAYNAKLAR}

1. Kroiss F. Die Verletzungen der Kniegelenkoszwischenknorpel und ihrer Verbindungen. Beitr Klin Chir 1910;66:598-801.

2. Andrish JT. Meniscal Injuries in Children and Adolescents: Diagnosis and Management. J Am Acad Orthop Surg 1996;4(5):231-7. Crossref

3. Kaplan EB. Discoid lateral meniscus of the knee joint; nature, mechanism, and operative treatment. J Bone Joint Surg Am 1957;39-A(1):77-87. Crossref

4. Arnoczky SP, Warren RF. Microvasculature of the human meniscus. Am J Sports Med 1982;10(2):90-5. Crossref

5. Kim SJ, Kim DW, Min BH. Discoid lateral meniscus associated with anomalous insertion of the medial meniscus. Clin Orthop Relat Res 1995;(315):234-7. Crossref

6. Nathan PA, Cole SC. Discoid meniscus. A clinical and pathologic study. Clin Orthop Relat Res 1969;64:107-13.

7. Atay OA, Pekmezci M, Doral MN, Sargon MF, Ayvaz M, Johnson DL. Discoid meniscus: an ultrastructural study with transmission electron microscopy. Am J Sports Med 2007;35(3):475-8. Crossref

8. Papadopoulos A, Karathanasis A, Kirkos JM, Kapetanos GA. Epidemiologic, clinical and arthroscopic study of the discoidmeniscus variant in Greek population. Knee Surg Sports Traumatol Arthrosc 2009;17(6):600-6. Crossref

9. Monllau JC, León A, Cugat R, Ballester J. Ring-shaped lateral meniscus. Arthroscopy 1998;14(5):502-4. Crossref

10. Arnold MP, van Kampen A. Symptomatic ring-shaped lateral meniscus. Arthroscopy 2000;16(8):852-4. Crossref

11. Atay OA, Doral MN, Leblebicioğlu G, Tetik O, Aydıngöz U. Management of discoid lateral meniscus tears: observations in 34 knees. Arthroscopy 2003;19(4):346-52. Crossref 
12. Jordan MR. Lateral Meniscal Variants: Evaluation and Treatment. J Am Acad Orthop Surg 1996;4(4):191-200. Crossref

13. Vandermeer RD, Cunningham FK. Arthroscopic treatment of the discoid lateral meniscus: results of long-term follow-up. Arthroscopy 1989;5(2):101-9. Crossref

14. Doral MN, Karlsson J, editors. Sports Injuries; Prevention, Diagnosis, Treatment and Rehabilitation, 2nd ed. USA: Springer; 2015.

15. Patel NM, Cody SR, Ganley TJ. Symptomatic bilateral discoid menisci in children: a comparison with unilaterally symptomatic patients. J Pediatr Orthop 2012;32(1):5-8. Crossref

16. Aichroth PM, Patel DV, Marx CL. Congenital discoid lateral meniscus in children. A follow-up study and evolution of management. J Bone Joint Surg Br 1991;73-B(6):932-6. Crossref

17. Klingele KE, Kocher MS, Hresko MT, Gerbino P, Micheli LJ. Discoid lateral meniscus: prevalence of peripheral rim instability. J Pediatr Orthop 2004;24(1):79-82. Crossref

18. Rao SK, Sripathi Rao P. Clinical, radiologic and arthroscopic assessment and treatment of bilateral discoid lateral meniscus. Knee Surg Sports Traumatol Arthrosc 2007;15(5):597-601. Crossref

19. Ahn JH, Lee $\mathrm{SH}$, Yoo JC, Lee HJ, Lee JS. Bilateral discoid lateral meniscus in knees: evaluation of the contralateral knee in patients with symptomatic discoid lateral meniscus. Arthroscopy 2010;26(10):1348-56. Crossref

20. Watanabe M, Takeda SJ, Ikeuchi HJ. Atlas of Arthroscopy, 3rd ed. Berlin: Springer-Verlag; 1979.

21. Smillie IS. The congenital discoid meniscus. J Bone Joint Surg $\mathrm{Br}$ 1948;30-B(4):671-82. Crossref

22. Neuschwander DC, Drez D Jr, Finney TP. Lateral meniscal variant with absence of the posterior coronary ligament. J Bone Joint Surg Am 1992;74(8):1186-90. Crossref

23. Ikeuchi $\mathrm{H}$. Arthroscopic treatment of the discoid lateral meniscus. Technique and long-term results. Clin Orthop Relat Res 1982;(167):19-28. Crossref

24. Albertsson M, Gillquist J. Discoid lateral menisci: a report of 29 cases. Arthroscopy 1988;4(3):211-4. Crossref

25. Fujikawa K, Iseki F, Mikura Y. Partial resection of the discoid meniscus in the child's knee. J Bone Joint Surg Br 1981;63$\mathrm{B}(3): 391-5$. Crossref

26. Dickhaut SC, DeLee JC. The discoid lateral-meniscus syndrome. J Bone Joint Surg Am 1982;64(7):1068-73. Crossref

27. Noble J. Lesions of the menisci. Autopsy incidence in adults less than fifty-five years old. J Bone Joint Surg Am 1977;59(4):480-3. Crossref

28. Woods GW, Whelan JM. Discoid meniscus. Clin Sports Med 1990;9(3):695-706

29. Le Minor JM. Comparative morphology of the lateral meniscus of the knee in primates. J Anat 1990;170:161-71.

30. Hayashi LK, Yamaga H, Ida K, Miura T. Arthroscopic meniscectomy for discoid lateral meniscus in children. J Bone Joint Surg Am 1988;70(10):1495-500. Crossref

31. Ahn JH, Lee YS, Ha HC, Shim JS, Lim KS. A novel magnetic resonance imaging classification of discoidlateral meniscus based on peripheral attachment. Am J Sports Med 2009;37(8):1564-9. Crossref

32. Rao PS, Rao SK, Paul R. Clinical, radiologic, and arthroscopic assessment of discoid lateral meniscus. Arthroscopy 2001;17(3):275-7. Crossref
33. Dickason JM, Del Pizzo W, Blazina ME, Fox JM, Friedman MJ, Snyder SJ. A series of ten discoid medial menisci. Clin Orthop Relat Res 1982;(168):75-9. Crossref

34. Bin SI, Jeong SI, Kim JM, Shon HC. Arthroscopic partial meniscectomy for horizontal tear of discoid lateral meniscus. Knee Surg Sports Traumatol Arthrosc 2002;10(1):20-4. Crossref

35. Pellacci F, Montanari G, Prosperi P, Galli G, Celli V. Lateral discoid meniscus: treatment and results. Arthroscopy 1992;8(4):526-30. Crossref

36. Bellier G, Dupont JY, Larrain M, Caudron C, Carlioz H. Lateral discoid menisci in children. Arthroscopy 1989;5(1):52-6. Crossref

37. Kim YG, Ihn JC, Park SK, Kyung HS. An arthroscopic analysis of lateral meniscal variants and a comparison with MRI findings. Knee Surg Sports Traumatol Arthrosc 2006;14(1):20-6. Crossref

38. Washington ER 3rd, Root L, Liener UC. Discoid lateral meniscus in children. Long-term follow-up after excision. J Bone Joint Surg Am 1995;77(9):1357-61. Crossref

39. Carter CW, Hoellwarth J, Weiss JM. Clinical outcomes as a function of meniscal stability in the discoidmeniscus: a preliminary report. J Pediatr Orthop 2012;32(1):9-14. Crossref

40. Ahn JH, Shim JS, Hwang $\mathrm{CH}$, Oh WH. Discoid lateral meniscus in children: clinical manifestations and morphology. J Pediatr Orthop 2001;21(6):812-6. Crossref

41. Yoshida S, Ikata T, Takai H, Kashiwaguchi S, Katoh S, Takeda Y. Osteochondritis dissecans of the femoral condyle in the growth stage. Clin Orthop Relat Res 1998;(346):162-70. Crossref

42. Irani RN, Karasick D, Karasick S. A possible explanation of the pathogenesis of osteochondritis dissecans. J Pediatr Orthop 1984;4(3):358-60. Crossref

43. Mitsuoka T, Shino K, Hamada M, Horibe S. Osteochondritis dissecans of the lateral femoral condyle of the knee joint. Arthroscopy 1999;15(1):20-6. Crossref

44. Kramer DE, Micheli LJ. Meniscal tears and discoid meniscus in children: diagnosis and treatment. J Am Acad Orthop Surg 2009;17(11):698-707. Crossref

45. Kushare I, Klingele K, Samora W. Discoid Meniscus: Diagnosis and Management. Orthop Clin North Am 2015;46(4):53340. Crossref

46. Kocher MS, DiCanzio J, Zurakowski D, Micheli LJ. Diagnostic performance of clinical examination and selective magnetic resonance imaging in the evaluation of intraarticular knee disorders in children and adolescents. Am J Sports Med 2001;29(3):292-6. Crossref

47. Hamada M, Shino K, Kawano K, Araki Y, Matsui Y, Doi T. Usefulness of magnetic resonance imaging for detecting intrasubstance tear and/or degeneration of lateral discoid meniscus. Arthroscopy 1994;10(6):645-53. Crossref

48. Ryu KN, Kim IS, Kim EJ, Ahn JW, Bae DK, Sartoris DJ, Resnick D. MR imaging of tears of discoid lateral menisci. AJR Am J Roentgenol 1998;171(4):963-7. Crossref

49. Kocher MS, Logan CA, Kramer DE. Discoid Lateral Meniscus in Children: Diagnosis, Management, and Outcomes. J Am Acad Orthop Surg 2017;25(11):736-43. Crossref

50. Fairbank TJ. Knee joint changes after meniscectomy. J Bone Joint Surg Br 1948;30-B(4):664-70. Crossref

51. Manzione M, Pizzutillo PD, Peoples AB, Schweizer PA. Meniscectomy in children: a long-term follow-up study. Am J Sports Med 1983;11(3):111-5. Crossref 
52. Räber DA, Friederich NF, Hefti F. Discoid lateral meniscus in children. Long-term follow-up after total meniscectomy. J Bone Joint Surg Am 1998;80(11):1579-86. Crossref

53. Baratz ME, Fu FH, Mengato R. Meniscal tears: the effect of meniscectomy and of repair on intraarticular contact areas and stress in the human knee. A preliminary report. Am J Sports Med 1986;14(4):270-5. Crossref

54. Smith CF, Van Dyk GE, Jurgutis J, Vangsness CT Jr. Cautious surgery for discoid menisci. Am J Knee Surg 1999;12(1):25-8.

55. Sugawara O, Miyatsu M, Yamashita I, Takemitsu Y, Onozawa $T$. Problems with repeated arthroscopic surgery in the discoid meniscus. Arthroscopy 1991;7(1):68-71. Crossref

56. Yilgor C, Atay OA, Ergen B, Doral MN. Comparison of magnetic resonance imaging findings with arthroscopic findings in discoid meniscus. Knee Surg Sports Traumatol Arthrosc 2014;22(2):268-73. Crossref

57. Tegner Y, Lysholm J. Rating systems in the evaluation of knee ligament injuries. Clin Orthop Relat Res 1985;(198):43-9. Crossref

58. Good CR, Green DW, Griffith MH, Valen AW, Widmann RF, Rodeo SA. Arthroscopic treatment of symptomatic discoid meniscus in children: classification, technique, and results. Arthroscopy 2007;23(2):157-63.e1. Crossref
59. Oğüt T, Kesmezacar H, Akgün I, Cansü E. Arthroscopic meniscectomy for discoid lateral meniscus in children and adolescents: 4.5 year follow-up. J Pediatr Orthop B 2003;12(6):390-7. Crossref

60. Davidson D, Letts $M$, Glasgow R. Discoid meniscus in children: treatment and outcome. Can J Surg 2003;46(5):350-8.

61. Ahn JH, Kim KI, Wang JH, Jeon JW, Cho YC, Lee SH. Long-term results of arthroscopic reshaping for symptomatic discoid lateral meniscus in children. Arthroscopy 2015;31(5):86773. Crossref

62. Kose O, Celiktas M, Egerci OF, Guler F, Ozyurek S, Sarpel $Y$. Prognostic factors affecting the outcome of arthroscopic saucerization in discoid lateral meniscus: a retrospective analysis of 48 cases. Musculoskelet Surg 2015;99(2):165-70. Crossref

63. Kim JM, Bin SI. Meniscal allograft transplantation after total meniscectomy of torn discoid lateral meniscus. Arthroscopy 2006;22(12):1344-50.e1. Crossref

64. Yoon JR, Jeong HI, Seo MJ, Jang KM, Oh SR, Song S, Yang $\mathrm{JH}$. The use of contralateral knee magnetic resonance imaging to predict meniscal size during meniscal allograft transplantation. Arthroscopy 2014;30(10):1287-93. Crossref 